Tetrahedron Letters

journal homepage: www.elsevier.com

\title{
Evaluation of dipole moment and electrophilicity on the nature of click-type coupling reaction between thioamide and sulfonyl azide
}

\author{
Muhammad Aswad, *Junya Chiba, Takenori Tomohiro, Yasumaru Hatanaka \\ Graduate School of Medicine and Pharmaceutical Sciences, University of Toyama, 2630 Sugitani, Toyama 930-0194, Japan
}

\section{ARTICLE INFO}

ABSTRACT

Article history:

Received

Received in revised form

Accepted

Available online

\section{Keywords:}

Thioamide

Dipole moment

Sulfonyl azide

Electrophilicity

Coupling reaction
A cooperated experimental and computational investigation on sulfonyl amidine formation from thioamides and sulfonyl azides is described. The data support a non-concerted two-step pathway for the coupling reaction and also indicate that dipole moment of thioamide and electrophilicity of sulfonyl azide would be significant factors for the reaction efficiency. A simple reactivity prediction of the coupling reaction was demonstrated by preliminary in silico evaluation for these factors, by which we successfully picked up a good pair of reactants with high reactivity among several thioamides and sulfonyl azides in stock.

2009 Elsevier Ltd. All rights reserved
Click-type reaction has become increasingly important as the powerful approach of bio-orthogonal ligation method. ${ }^{1} \mathrm{We}$ recently reported a new class of click-type chemoselective reaction between thioamides and sulfonyl azides that furnishes sulfonyl amidines in the absence of any activation additives. ${ }^{2}$ The reaction proceeds by mixing a thioamide and a sulfonyl azide at room temperature in various solvents. Increment of the solvent polarity enhances the reaction efficiency and water displayed the highest performance among solvents examined. These features of reaction well satisfy the prerequisite for the biological application. The solvent effect also suggests that the ionic resonance form of thioamides could be preferentially stabilized in polar protic solvents to accelerate the coupling reaction. In the previous report, we suggested an analogous mechanism to the coupling reaction of sulfonyl azides with thioacid derivatives (sulfo-click reaction), ${ }^{3}$ in which ionic states mainly contribute to the mechanism. In this report, we disclose a non-concerted twostep pathway for the coupling reaction based on both of the experimental and computational investigation of the reaction efficiency by varying the substituents on the respective phenyl rings in thioacetanilide and benzenesulfonyl azide, which enabled to design a combination of thioamide and sulfonyl azide resulting the desired amidine very efficiently in a high yield.

Scheme 1 shows possible two pathways for the coupling reaction in analogy to the proposed mechanism for the sulfo-click reaction $^{3 \mathrm{~b}, \mathrm{c}}$ and 1,3-dipoler cycloadditions of organic azides and cyclic ketene derivatives. ${ }^{4}$ Thioamide derivatives favorably transform to the resonance structures ${ }^{5} \mathrm{~T}^{*}$ that can react with electron-poor sulfonyl azides by an initial bond-formation

* Corresponding author. E-mail: chiba@pha.u-toyama.ac.jp

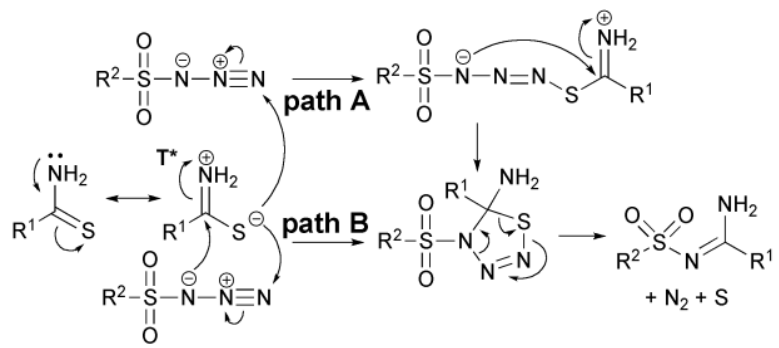

Scheme 1. Two plausible pathways of the coupling reaction
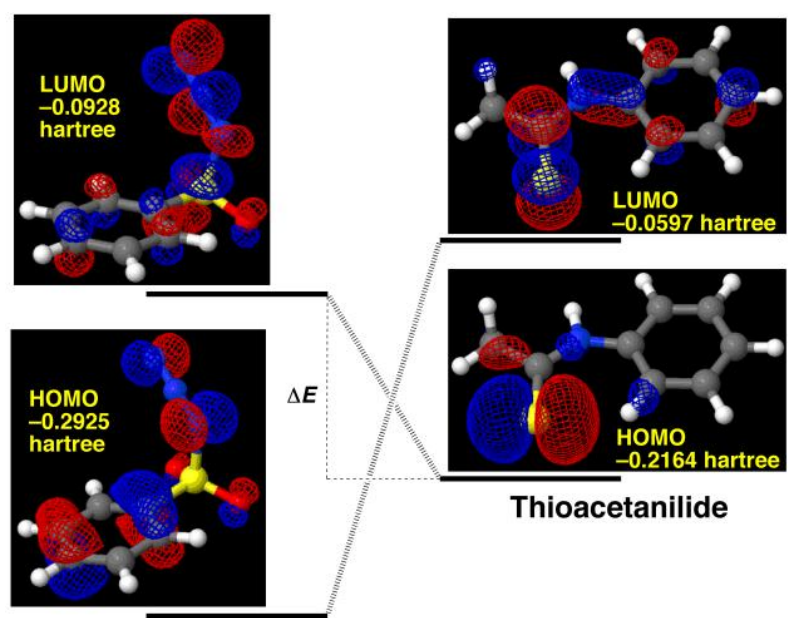

Thioacetanilide

\section{Benzenesulfonyl azide}

Figure 1. Energy levels of the frontier orbitals for benzenesulfonyl azide 1a (left side) and thioacetanilide $\mathbf{2 a}$ (right side) estimated by DFT (RB3LYP/6-311+G(d,p)) calculation. $\Delta E$ indicates energy difference of frontier orbitals. The sturctures are visualized with Jmol. ${ }^{9}$ 
Tetrahedron Letters

Table 1. Reactivity of substituted benzenesulfonyl azides

\begin{tabular}{|c|c|c|c|c|c|c|c|c|c|}
\hline entry & $\mathrm{BA}^{\mathrm{a}}$ & $\mathrm{R}^{1}$ & $\mathrm{P}^{\mathrm{b}}$ & Time $^{c}$ & Yield $^{d}$ & Charge of $\mathrm{N}_{3}{ }^{\mathrm{e}}$ & Reactivity $^{f}$ & LUMO $^{g}$ & $\Delta E^{\mathrm{h}} \times 10^{4}$ \\
\hline 1 & $1 \mathrm{a}$ & $\mathrm{H}$ & $3 \mathbf{a}$ & 20 & 63 & -0.035 & moderate & -0.0928 & 1236 \\
\hline 2 & $1 b$ & $4-\mathrm{CH}_{3}$ & $3 b$ & 20 & 46 & -0.038 & moderate & -0.0896 & 1268 \\
\hline 3 & $1 c$ & $4-\mathrm{OCH}_{3}$ & $3 c$ & 20 & 38 & -0.042 & low & -0.0868 & 1296 \\
\hline 4 & 1d & $3-\mathrm{NO}_{2}$ & 3d & 20 & 84 & 0.005 & good & -0.1304 & 860 \\
\hline 5 & $1 \mathrm{e}$ & $3-\mathrm{CF}_{3}$ & $3 \mathbf{e}$ & 17 & 95 & 0.009 & good & -0.1033 & 1131 \\
\hline 6 & 1f & 3,5-bis- $\mathrm{CF}_{3}$ & $3 f$ & 7 & 93 & 0.046 & very good & -0.1144 & 1020 \\
\hline
\end{tabular}

$[\mathbf{1}]=1.0 \mathrm{M},[2]=0.5 \mathrm{M}$. ${ }^{\mathrm{a}}$ Substituted benzenesulfonyl azide. ${ }^{\mathrm{b}}$ Product (sulfonyl amidine derivative). ${ }^{\mathrm{c}}$ Reaction time (h). ${ }^{\mathrm{d}}$ Isolated yield (\%). ${ }^{\mathrm{e}} \mathrm{Charge}$ of the azide group based on the electron density (total Mulliken population) of the three nitrogen atoms constructing the azide estimated by DFT calculation (RB3LYP/6$311+\mathrm{G}(\mathrm{d}, \mathrm{p})) .{ }^{\mathrm{f}} \mathrm{Based}$ on the isolated yield: low $(0-45 \%)$, moderate (45-75\%), good (75-100\%), and very good (75-100\% within $\left.10 \mathrm{~h}\right) .{ }^{\mathrm{g}} \mathrm{LUMO}$ energy (hartree). ${ }^{\text {h}}$ Energy difference (hartree) of the frontier orbitals between LUMO of 1a-f and HOMO of 2a $(-0.2164$ hartree).

between sulfur and nitrogen to give a linear adduct, followed by forming an intramolecular nitrogen-carbon bond to afford a thiatriazoline intermediate (path A). Succeeding retro-[3+2] cycloaddition furnishes sulfonyl amidine derivatives associated with $\mathrm{N}_{2}$ gas generation and solid sulfur precipitation. Another pathway denoted as path $\mathrm{B}$ could be anticipated that $\mathrm{T}^{*}$ can react with electron-deficient sulfonyl azides by simultaneous formation of sulfur-nitrogen and nitrogen-carbon bonds in a single [3+2] cycloaddition step to give the same thiatriazoline intermediate as path A.

To estimate the initial step of the reaction, we conducted density functional theory (DFT) calculation for benzenesulfonyl azide $\mathbf{1 a}$ and thioacetanilide $\mathbf{2 a}$ in the ground state (RB3LYP/6$311+\mathrm{G}(\mathrm{d}, \mathrm{p})$, see Supplementary data in detail). ${ }^{6}$ Figure 1 displays the frontier orbitals of the two compounds and their energy levels. This energy diagram clearly shows that the combination for the HOMO of thioacetanilide and the LUMO of benzenesulfonyl azide is energetically more reactive than the other HOMO-LUMO combination. In the former reactive combination, the HOMO-localization on sulfur of the thioamide was visualized as Figure 1 in contrast to almost no orbital phase on thiocarbonyl-carbon, suggesting that the sulfur would attack initially to the terminal nitrogen of the azide having the compatible LUMO phase with the sulfur. Subsequent intramolecular cyclization of the linear adduct gives a thiatriazoline by a nucleophilic attack to thiocarbonyl-carbon from azide-nitrogen adjacent to the sulfonyl-sulfur. The frontier orbitals in the less-reactive combination exhibit well-matched orbital phases between the nitrogen (HOMO) and the thiocarbonyl-carbon (LUMO). Although the HOMO-LUMO energy gap is relatively large, the desired nitrogen-carbon linkage would successively form because the two related atoms are intramolecularly settled at near position after the generation of the linear adduct. In addition, thioacetamide and 2-thiopiperidone have almost the same orbital phases as thioacetanilide in both HOMO and LUMO (Figure S1), therefore, the estimated reaction pathway would seem to be extensible to the coupling reaction in general. These computational examination revealed that the coupling reaction of thioamides and sulfonyl azides would prefer to go for the path $\mathrm{A}$ in Figure 1 rather than the path $\mathrm{B}$, the simultaneous two-bonds formation via concerted [3+2] cycloaddition, which is similar to the reported mechanism for sulfo-click reaction with electron-deficient azides. ${ }^{3 \mathrm{~b}, \mathrm{c}}$

Based on the above computational estimation, we first anticipated that electrophilicity of the azide group may play an important role for the reactivity of the coupling reaction. Thus, we compared the electrophilicity, the computed charge of $\mathrm{N}_{3}$, with the experimental reactivity of the coupling reactions performed by means of substituted benzenesulfonyl azides 1a-f and thioacetanilide 2a (Table 1). With the increasing of the negativity on azide, the isolated yields for $\mathbf{1 b}$ and $\mathbf{1 c}$ fell down in comparison to that for 1a (entries 1-3 in Table 1). The electrondonating groups reduced the charge of $\mathrm{N}_{3}$ accompanied by raising LUMO energy level to be unstable, giving rise to the low isolated yields. On the other hand, electron-withdrawing groups on its phenyl ring seems to improve the reactivity (entries 4-6). Single functional group-substitution by $-\mathrm{NO}_{2}$ or $-\mathrm{CF}_{3}$ afforded good isolated yields with somewhat positive $\mathrm{N}_{3}$-charge relative to the above 1a-c. $\mathrm{NO}_{2}$-substituted 1d has the most stable LUMO level among the sulfonyl azide compounds in this report. Of course the narrow HOMO-LUMO gap $\Delta E$ is no doubt an important factor for the reactivity, however, electrophilicity of the azide group seems to be a dominant factor for the coupling reaction. $\mathrm{Bis}-\mathrm{CF}_{3}$ substitution on the phenyl ring supported this evaluation, that is, $\mathbf{1 f}$ exhibited good reactivity in shorter reaction time of $7 \mathrm{~h}$ with greater azide's positive-charge in spite of the $\Delta E$ for $\mathbf{1 f}$ is larger than that for $\mathbf{1 d}$, indicating the importance of the electrophilicity so that stepwise, electrostatic-type mechanism of path A would be preferred rather than the concerted $[3+2]$ cycloaddition-type path $B$. To check the reproducibility of the yields of the coupling reaction, $\mathbf{3 a}$ and $\mathbf{3 f}$ were synthesized in 3 runs, affording small deviations of the yields within $\pm 5 \%$ in both cases.

Next, we anticipated for thioamides that both of the nucleophilicity on sulfur $(\delta)$ and the electrophilicity on thiocarbonyl-carbon $\left(\delta^{+}\right)$would be important for the reactivity based on the reaction mechanism of path A. In other word, dipole moment of thioamides would seemingly influence to the reactivity. Thus, we systematically varied the substituents on the phenyl ring of thioacetanilide (Table 2). Since each thioamide derivative shows its dipole moment with different direction, a decomposed-vector component of the dipole moment along with the $\mathrm{C}=\mathrm{S}$ double-bond orientation, $\mathrm{D}_{\mathrm{C}=\mathrm{S}}$, is brought into for fair comparison toward the reactivity. Methyl-substituted $\mathbf{2 b}$ showed moderate reactivity with almost the same isolated yield and $\mathrm{D}_{\mathrm{C}=\mathrm{S}}$ as those for 2a (entry 1,2). By means of the introduction of $\mathrm{MeO}-$ group, 2c exhibited small $\mathrm{D}_{\mathrm{C}=\mathrm{S}}$ of 3.2 debye with low reactivity in an isolated yield of $37 \%$ (entry 3 ). In contrast, $\mathbf{2 f}$ displayed high $\mathrm{D}_{\mathrm{C}=\mathrm{S}}$ of 5.0 debye with good reactivity in $81 \%$ yield (entry 6). As a consequence, $\mathrm{D}_{\mathrm{C}=\mathrm{S}}$ would be a good indicator for the reactivity. On the other hand, $\mathrm{NO}_{2}$-tethered $\mathbf{2 d}$ displayed slightly large $\mathrm{D}_{\mathrm{C}=\mathrm{S}}$ but low isolated yield, owing to the very large $\Delta E$ originated from the significant stabilization of HOMO energy level for $\mathbf{2 d}$ by the introduction of a powerful electron-withdrawing nitro-group (entry 4). The similar tendency was observed for $\mathbf{2} \mathbf{g}$ possessing two electron-withdrawing groups 
Table 2. Reactivity of substituted thioacetanilides

\begin{tabular}{|c|c|c|c|c|c|c|c|c|c|c|c|}
\hline entry & $\mathrm{TA}^{\mathrm{a}}$ & $\mathrm{R}^{2}$ & $\mathrm{P}^{\mathrm{b}}$ & Time $^{c}$ & Yield $^{d}$ & Dipole $^{e}$ & $\mathrm{D}_{\mathrm{C}=\mathrm{s}}^{\mathrm{f}}$ & $\Delta \mathrm{D}_{\mathrm{C}=\mathrm{s}^{\mathrm{g}}}$ & Reactivity $^{\mathrm{h}}$ & $\mathrm{HOMO}^{\mathrm{i}}$ & $\Delta E^{\mathrm{j}} \times 10^{4}$ \\
\hline 1 & $2 a$ & $\mathrm{H}$ & $3 \mathbf{3 a}$ & 20 & 63 & 4.2 & 4.1 & 0 & moderate & -0.2164 & 1236 \\
\hline 2 & $2 b$ & $4-\mathrm{CH}_{3}$ & $3 g$ & 20 & 65 & 4.4 & 4.1 & 0 & moderate & -0.2138 & 1212 \\
\hline 3 & $2 c$ & $4-\mathrm{OCH}_{3}$ & $3 \mathbf{h}$ & 20 & 37 & 3.5 & 3.2 & -0.9 & low & -0.2119 & 1191 \\
\hline 4 & $2 d$ & $4-\mathrm{NO}_{2}$ & $3 \mathbf{i}$ & 20 & 31 & 6.6 & 4.4 & 0.3 & low & -0.2361 & 1433 \\
\hline 5 & $2 e$ & $4-\mathrm{F}$ & $3 \mathbf{j}$ & 20 & 73 & 4.3 & 4.3 & 0.2 & moderate & -0.2211 & 1283 \\
\hline 6 & $2 \mathrm{f}$ & $4-\mathrm{CF}_{3}$ & $3 \mathbf{k}$ & 20 & 81 & 5.0 & 5.0 & 0.9 & good & -0.2287 & 1359 \\
\hline 7 & $2 \mathrm{~g}$ & 3,5-bisCF 3 & 31 & 20 & 40 & 4.8 & 4.2 & 0.1 & low & -0.2366 & 1438 \\
\hline
\end{tabular}

$[\mathbf{1}]=1.0 \mathrm{M},[\mathbf{2}]=0.5 \mathrm{M} .{ }^{a}$ Substituted thioacetanilide. ${ }^{b}$ Product (sulfonyl amidine derivative). ${ }^{\mathrm{c}}$ Reaction time (h). ${ }^{\mathrm{d}}$ Isolated yield (\%). ${ }^{\mathrm{e}}$ Dipole moment (debye) of 2 estimated by DFT calculation (RB3LYP/6-311+G(d,p)). . Decomposed dipole moment (debye) along the $\mathrm{C}=\mathrm{S}$ orientation. ${ }^{\mathrm{g}}$ Difference of $\mathrm{D}_{\mathrm{C}=\mathrm{S}}(\mathrm{debye})$ between

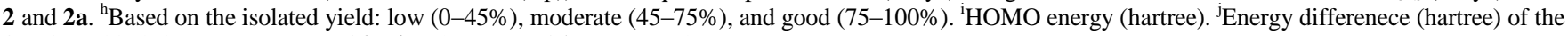
frontier orbitals between HOMO of $\mathbf{2 a - i}$ and LUMO of $\mathbf{1 a}(-0.0928$ hartree).

Table 3. In silico evaluation of $\mathrm{N}_{3}$-electrophilicity and dipole moment for a reactivity prediction of the coupling reaction.

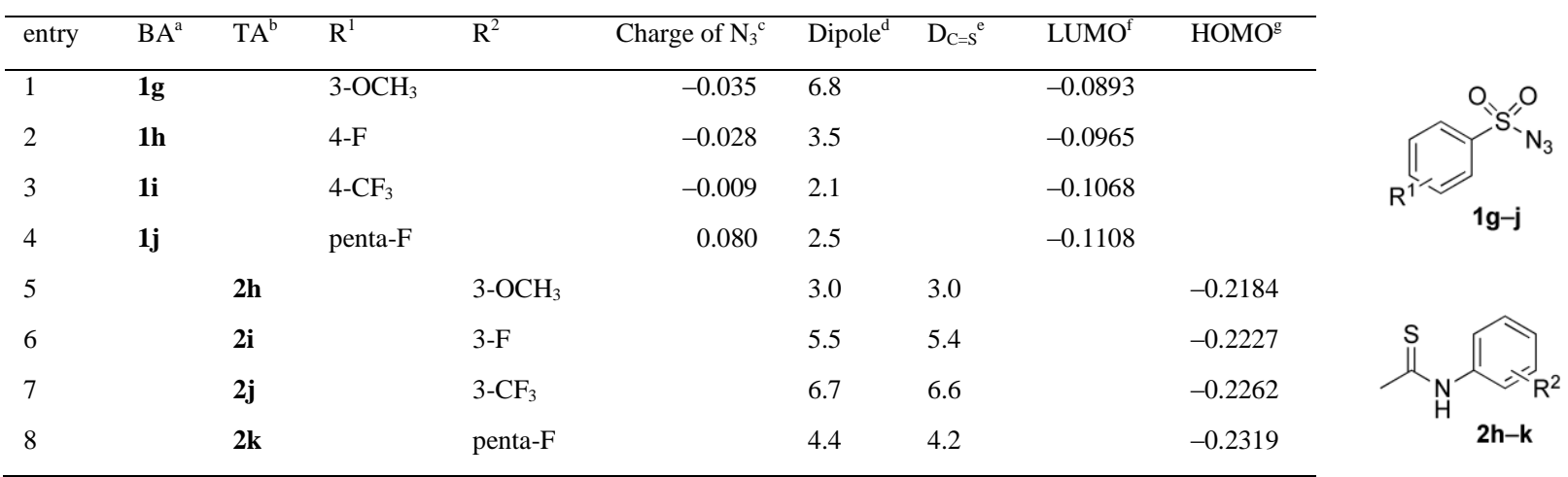

${ }^{a}$ Substituted benzenesulfonyl azide. ${ }^{b}$ Substituted thioacetanilide. ${ }^{\mathrm{c}}$ Charge of the azide group based on the electron density (total Mulliken population) of the three nitrogen atoms constructing the azide estimated by DFT calculation (RB3LYP/6-311+G(d,p)). ${ }^{\mathrm{d}}$ Dipole moment (debye). ${ }^{\mathrm{e}}$ Decomposed dipole moment (debye) along the $\mathrm{C}=\mathrm{S}$ orientation. ${ }^{\mathrm{f}} \mathrm{LUMO}$ energy (hartree). ${ }^{\mathrm{g}} \mathrm{HOMO}$ energy (hartree).

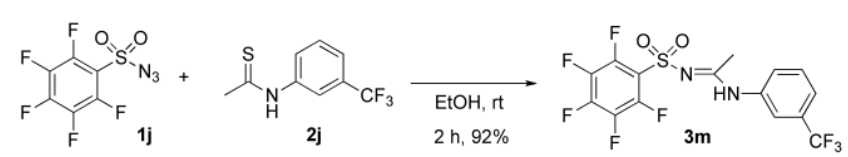

Scheme 2. The coupling reaction selected by the in silico estimation.

and a large $\Delta E$ with a moderate $\mathrm{D}_{\mathrm{C}=\mathrm{S}}$, providing low reactivity (entry 7). These findings indicate that $\Delta E$ would be an important factor as well as $\mathrm{D}_{\mathrm{C}=\mathrm{S}}$ for the reactivity. Fluorine-substituted $\mathbf{2 f}$ afforded moderate reactivity with slightly favorable $\mathrm{D}_{\mathrm{C}=\mathrm{S}}$ and somewhat unfavorable $\Delta E$, suggesting the importance of balance between $\Delta E$ and $\mathrm{D}_{\mathrm{C}=\mathrm{S}}$ for the reactivity (entry 5 ).

Finally, with the aim of predicting the efficiency of the coupling reaction, we simply estimated charge of $\mathrm{N}_{3}$ and $\mathrm{D}_{\mathrm{C}=\mathrm{S}}$ as well as the energy of frontier orbitals by preliminary DFT calculation for the additional four types of substituted benzenesulfonyl azides and thioacetanilides in stock (Table 3). Pentafluoro-substituted benzensulfonyl azides $\mathbf{1 j}$ retained large positive $\mathrm{N}_{3}$-charge while $\mathbf{2} \mathbf{j}$ showed great $\mathrm{D}_{\mathrm{C}=\mathrm{S}}$ and not too-stable HOMO-energy level. Therefore, it was presumable that $\mathbf{1} \mathbf{j}$ and $\mathbf{2} \mathbf{j}$ would be the most reactive combination in Table 3. As expected, simple mixing of $\mathbf{1} \mathbf{j}$ and $\mathbf{2} \mathbf{j}$ in EtOH at room temperature afforded the product amidine $\mathbf{3 m}$ in a good isolated yield within $2 \mathrm{~h}$
(Scheme 2). Expansion the prediction to the coupling reaction in general as well as detailed transition-state analysis in silico is now underway.

\section{Acknowledgments}

This research was supported by Grants-in-Aid for Scientific Research (25350976 (J.C.)) from the Ministry of Education, Culture, Sports, Science and Technology of Japan, and Adaptable and Seamless Technology Transfer Program (A-STEP, AS262Z01488Q (J.C.)) through target-driven R\&D, JST.

\section{References and notes}

1. (a) Kolb, H. C.; Finn, M. G.; Sharpless, K. B. Angew. Chem. Int. Ed. 2001, 40, 2004-2021; (b) Prescher, J. A.; Bertozzi, C. R. Nat. Chem. Biol. 2005, 1, 13-21; (c) Click Chemistry for Biotechnology and Material Science, Lahann, J., Ed.; Wiley: U. K., 2009; (d) Sletten, E. M.; Bertozzi, C. R. Acc. Chem. Res. 2011, 
44, 666-676; (e) Heaney, F. Eur. J. Org. Chem. 2012, 30433058; (f) Grammel, M.; Hang, H. C. Nat. Chem. Biol. 2013, 9 , 475-484.

2. Aswad, M.; Chiba, J.; Tomohiro, T.; Hatanaka, Y. Chem. Commun. 2013, 49, 10242-10244.

3. (a) Shangguan, N.; Katukojvala, S.; Greenberg, R.; Williams, L. J. J. Am. Chem. Soc. 2003, 125, 7754-7755; (b) Kolakowski, R. V.; Shangguan, N.; Sauers, R. R.; Williams, L. J. J. Am. Chem. Soc. 2006, 128, 5695-5702; (c) Gao, Y. Cent. Eur. J. Chem. 2010, 8, 308-319; (d) Rijkers, D. T. S.; Merkx, R.; Yim, C.-B.; Brouwer, A. J.; Liskamp, R. M. J. J. Pept. Sci. 2010, 16, 1-5: (e) Xie, S.; Fukumoto, R.; Ramström, O.; Yan, M. J. Org. Chem. 2015, 80, 4392-4397.

4. Quast, H.; Ach, M.; Balthasar, J.; Hergenröther, T.; Regnat, D.; Lehmann, J.; Banert, K. Helv. Chim. Acta. 2005, 88, 1589-1609.

5. (a) Laubergnat, D.; Hiberty, P. C. J. Am. Chem. Soc. 1997, 119, 9478-9482; (b) Wiberg, K. B.; Rush, D. J. J. Am. Chem. Soc. 2001, 123, 2038-2046.
6. DFT calculation was performed with Firefly QC package (version $8.1 .1),{ }^{7}$ which is partially based on the GAMESS (US) ${ }^{8}$ source code. First, the computation was executed on structural optimization by means of carefully selected input structures as mentioned in Supplementary data. The optimized structures were then checked by frequency calculation, by which we picked up several local minimum conformations with some detailed physical properties. Finally, single-point energy calculation was carried out for them, affording the most stable structure among the initial candidate structures. The computed structures were visualized with Jmol..$^{9}$

7. Granovsky, A. A. Firefly version 8.1.1, http://classic.chem.msu.su/gran/firefly/index.html.

8. Schmidt, M.W.; Baladridge, K. K.; Boatz, J. A.; Elbert, S. T.; Gordon, M. S.; Jensen, J. H.; Koseki, S.; Matsunaga, N.; Nguyen, K. A.; Su, S.; Windus, T. L.; Dupuis, M.; Montgomery, J. A. J. Comput. Chem. 1993, 14, 1347-1363.

9. Jmol: an open-source Java viewer for chemical structures in 3D (http://www.jmol.org/). 


\section{Graphical Abstract}

To create your abstract, type over the instructions in the template box below.

Fonts or abstract dimensions should not be changed or altered.

Evaluation of dipole moment and

electrophilicity on the nature of click-type

Leave this area blank for abstract info.

coupling reaction between thioamide and

sulfonyl azide

Muhammad Aswad, Junya Chiba, Takenori Tomohiro, Yasumaru Hatanaka<smiles>[R][R]1cccc(NC(C)=S)c1</smiles><smiles>CCO</smiles><smiles>[R][R]1ccc(N/C(C)=N/S(=O)(=O)c2ccc([R2])cc2)cc1</smiles> 